\title{
Unconventional biradical character of titanium enolates
}

\author{
Ibério de P. R. Moreira ${ }^{1, *}$, Josep Maria Bofill ${ }^{2}$, Josep Maria Anglada ${ }^{3}$, Joan G. Solsona ${ }^{2}$, \\ Joaquim Nebot ${ }^{2}$, Pere Romea and Fèlix Urpi ${ }^{2}$ \\ 1) Departament de Química Física, Universitat de Barcelona, c./ Martí i Franquès 1, 08028 \\ Barcelona, Catalunya, Spain. \\ 2) Departament de Química Orgànica, Universitat de Barcelona, c./ Martí i Franquès 1, 08028 \\ Barcelona, Catalunya, Spain. \\ 3) Institut de Investigacions Químiques i Ambientals de Barcelona, CSIC, Jordi Girona \\ Salgado 18-26, E-08034 Barcelona, Catalunya, Spain.
}

\section{Supporting Information}

\section{Details on the experimental procedure and ${ }^{1} \mathrm{H}$ and ${ }^{13} \mathrm{C}$ NMR spectra of titanium enolates from ketones 1 and 2.}

Two representative lactate-derived $\alpha$-hydroxy ketones have been considered to develop the present experimental analysis aiming to obtain detailed information about the formation mechanism of the corresponding enolates. These are 2-benzyloxy-3pentanone (or ketone 1) and 3-benzyloxy-2-butanone (or ketone 2).

The experimental procedure is as follows: 1.1 equivalents of neat $\mathrm{TiCl}_{4}$ are mixed with one equivalent of $\alpha$-hydroxy ketones 1 or 2 in $\mathrm{CH}_{2} \mathrm{Cl}_{2}\left(0.2 \mathrm{~mol} \mathrm{l}^{-1}\right)$ at $-78^{\circ} \mathrm{C}$ under $\mathrm{N}_{2}$ atmosphere to form the titanium(IV) complex. Adding dropwise 1.1 equivalents of diisopropylethylamine performs the enolization process and the resulting dark red solution is stirred for 1 hour. A fresh aliquot is extracted at $-78^{\circ} \mathrm{C}$ under $\mathrm{N}_{2}$ atmosphere and diluted to less than $0.1 \mathrm{~mol}^{-1}$ to proceed with the forthcoming spectroscopic analyses of the titanium enolate formed. The corresponding titanium enolates have been characterized by means of ${ }^{1} \mathrm{H}$ and ${ }^{13} \mathrm{C}$ NMR spectra which are in accordance with the proposed structures. General conditions for NMR spectra:

-1 $\mathrm{H}$ NMR: $\mathrm{CD}_{2} \mathrm{Cl}_{2}, 300 \mathrm{MHz},-78^{\circ} \mathrm{C}$

${ }^{\circ} \mathrm{C}$ NMR: $\mathrm{CD}_{2} \mathrm{Cl}_{2}, 75.4 \mathrm{MHz},-78^{\circ} \mathrm{C}$

The signals of the $\left[i-\mathrm{Pr}_{2} \mathrm{NHEt}\right]^{+}$cation have been omitted in the following description of NMR spectra.

1. Titanium enolate from ketone 1:

${ }^{1}$ H NMR: 7.50-7.45 (2H, m, ArH), 7.35-7.28 (3H, m, ArH), $5.31(1 \mathrm{H}$, br s, $\mathrm{PhCH} 2 \mathrm{O}), 4.75(1 \mathrm{H}$, br q, $J \approx 6.0, \mathrm{CHOTBS}), 4.10(1 \mathrm{H}, \mathrm{q}, J \approx 6.5,=\mathrm{CH}), 1.53(3 \mathrm{H}, \mathrm{d}$, $\left.J \approx 6.5,=\mathrm{CHCH}_{3}\right), \approx 1.35\left(\mathrm{CH}_{3}\right)$ This methyl group is masked by the proton signals of the $\left[i-\mathrm{Pr}_{2} \mathrm{NHEt}\right]^{+}$protonated base.

${ }^{13}$ C NMR: $160.6(\mathrm{OC}=), 135.5\left(\mathrm{C}_{A r}\right), 128.1\left(\mathrm{C}_{A r} \mathrm{H}\right), 127.9\left(\mathrm{C}_{A r} \mathrm{H}\right), 127.8\left(\mathrm{C}_{A r} \mathrm{H}\right), 93.8$ $(=\mathrm{CH}), 84.3(\mathrm{OCH}), 75.1\left(\mathrm{OCH}_{2}\right), 19.9 \& 10.9,\left(\mathrm{CH}_{3}\right)$. 


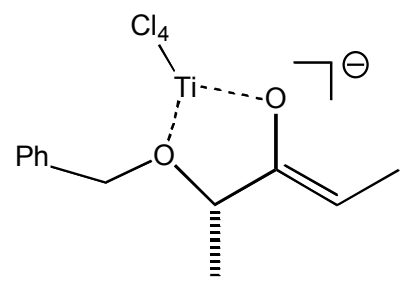

2. Titanium enolate from ketone 2:

${ }^{1}$ H NMR: 7.52-7.45 (2H, m, ArH), 7.40-7.28 (3H, m, ArH), $5.40(1 \mathrm{H}, \mathrm{d}, J=14.0$, $\left.\mathrm{PhCH}_{\mathrm{x}} \mathrm{H}_{\mathrm{y}} \mathrm{O}\right), 5.28\left(1 \mathrm{H}, \mathrm{d}, J=14.0, \mathrm{PhCH}_{\mathrm{x}} H_{\mathrm{y}} \mathrm{O}\right), 4.83(1 \mathrm{H}, \mathrm{q}, J=6.0, \mathrm{CHOTBN}), 3.94$ $\left(1 \mathrm{H}\right.$, br $\left.\mathrm{s},=\mathrm{CH}_{\mathrm{x}} \mathrm{H}_{\mathrm{y}}\right), 3.78\left(1 \mathrm{H}\right.$, br $\left.\mathrm{s},=\mathrm{CH}_{\mathrm{x}} H_{\mathrm{y}}\right), \approx 1.35\left(\mathrm{CH}_{3}\right)$ This methyl group is masked by the proton signals of the $\left[i-\mathrm{Pr}_{2} \mathrm{NHEt}\right]^{+}$protonated base.

${ }^{13}$ C NMR: $167.0(\mathrm{OC}=), 135.3\left(\mathrm{C}_{A r}\right), 128.1\left(\mathrm{C}_{A r} \mathrm{H}\right), 128.0\left(\mathrm{C}_{A r} \mathrm{H}\right), 127.9\left(\mathrm{C}_{A r} \mathrm{H}\right), 4.5$ $(\mathrm{OCH}), 81.7\left(=\mathrm{CH}_{2}\right), 75.8\left(\mathrm{OCH}_{2}\right), 19.1\left(\mathrm{CH}_{3}\right)$.<smiles>C=C1O[Te](Cl)OC1CO</smiles>

In Table S1 we summarize ${ }^{1} \mathrm{H}$ and ${ }^{13} \mathrm{C}$ NMR spectra of ketone $\mathbf{1}$, the ensuing $\mathrm{TiCl}_{4}$ complex and enolate. The comparison of the shifts shows that the structures undergo dramatic changes in accordance to the proposed structures (Scheme S1).

Scheme S1. Proposed structures for the complexes derived from ketone 1.<smiles>CCC(=O)[C@H](C)OCc1ccccc1</smiles><smiles>CCC1=C(C)[Al](Cl)O[C]1COc1ccccc1</smiles>

1<smiles>C/C=C1/O[I-](Cl)O[C@H]1COc1ccccc1</smiles>

Titanium enolate from 1

Characteristic downfield shifts for protons $\mathrm{H} 2$ and $\mathrm{H} 6$ and carbons $\mathrm{C} 2$, $\mathrm{C} 3$ and $\mathrm{C} 6$ observed for titanium complex (see entries 2, 5, 7, 8, and 11 of Table S1) prove the existence of a chelated Lewis acid-carbonyl complex similar to those reported in Ref. 1. Moreover, data arising from both spectra in the case of the enolate also agree with a chelated structure. 
Table S1. Significant ${ }^{1} \mathrm{H}$ and ${ }^{13} \mathrm{C}$ NMR chemical shifts (in ppm) of ketone $\mathbf{1}$, $\mathrm{TiCl}_{4}-1$ complex and the resulting enolate shown in Scheme S1.

\begin{tabular}{ccccc}
\hline Entry & Nucleus & $\delta$ in $\mathbf{1}^{\mathrm{a}}$ & $\delta$ in $\mathbf{T i C l}_{\mathbf{4}}-\mathbf{1}^{\mathrm{a}}$ & $\delta$ in enolate from $\mathbf{1}^{\mathrm{b}}$ \\
\hline 1 & $\mathrm{H} 1$ & 1.34 & 1.53 & --- $^{\mathrm{C}}$ \\
2 & $\mathrm{H} 2$ & 3.94 & 5.14 & 4.75 \\
3 & $\mathrm{H} 4$ & $2.55 \& 2.63$ & $2.84 \& 3.04$ & 4.10 \\
4 & $\mathrm{H} 5$ & 1.05 & 1.34 & 1.53 \\
5 & $\mathrm{H} 6$ & $4.49 \& 4.55$ & $5.31 \& 5.74$ & 5.31 \\
6 & $\mathrm{C} 1$ & 17.5 & 16.0 & 10.9 \\
7 & $\mathrm{C} 2$ & 80.5 & 88.7 & 84.3 \\
8 & $\mathrm{C} 3$ & 213.4 & 225.1 & 160.6 \\
9 & $\mathrm{C} 4$ & 30.5 & 31.9 & 93.8 \\
10 & $\mathrm{C} 5$ & 7.3 & 7.2 & 10.9 \\
11 & $\mathrm{C} 6$ & 71.8 & 80.9 & 75.1 \\
\hline
\end{tabular}

[a] In $\mathrm{CDCl}_{3}$ at $-50{ }^{\circ} \mathrm{C}$ [b] In $\mathrm{CD}_{2} \mathrm{Cl}_{2}$ at $-78{ }^{\circ} \mathrm{C}$ [c] Masked by protonated amine signals.

\section{Details on Theoretical Methods.}

Due to the complexity of these structures, a simplified molecular model was used for the theoretical description of the enolization process by means of ab initio wave function electronic structure calculations. To this end, $\alpha$-methoxyacetone was adopted as model system to represent $\alpha$-benzyloxy ketones $\mathbf{1}$ and $\mathbf{2}$ and diisopropylethylamine was replaced by ammonia. Since the reaction occurs in an apolar solvent $\left(\mathrm{CH}_{2} \mathrm{Cl}_{2}\right)$, all electronic structure calculations were carried out in vacuo for the representative process outlined in Scheme S2.

Scheme S2. Model system used for the theoretical description of the enolization process.

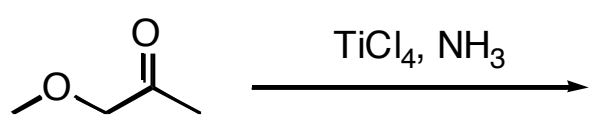<smiles></smiles>

The resulting energy profile for such enolization is shown in Figure 3 of the Communication.

All calculations presented in the Communication have been carried out employing the Los Alamos pseudopotential basis set (LANL2DZ) ${ }^{2}$ as well as the all 
electron 6-31G* basis set developed by Pople and collaborators. ${ }^{3}$ For the first stage of the reaction, namely, M1, M2, and the proton abstraction process with $\mathrm{NH}_{3}$ (TS1) to form CSS, we have employed a theoretical approach based on the Hartree-Frock (HF) functional since the electronic ground states of all these structures are closed-shell in nature. However, the study of the valence tautomerism between the two enolate intermediates, namely, CSS, TS2 and OSS, requires the use of a multireference approach as the complete active space self-consistent field (CASSCF) ${ }^{4}$ or the multireference configuration interaction $(\mathrm{MRCI})^{4,5}$ wave function approaches. The wave-function of open-shell electronic states such as OSS and $\mathbf{T}$ is dominated by the configurations arising from a four electrons in four orbitals space in which large static correlation effects take place whereas the CSS electronic state is strongly dominated by a closed shell configuration. Hence, the electronic ground-state of the structures involved in the relevant tautomeric equilibrium are both single and strongly multireference in nature and special cautions are needed to correctly describe open-shell systems. ${ }^{6}$ This fact precludes the application of DFT methods based on a single KohnSham determinant to represent the electronic states of the reported enolate structures. In addition, recent studies by Schreiner and co-workers ${ }^{7}$ have shown that, even for closed shell organic molecules, the accuracy of standard hybrid DFT potentials is questionable. For CASSCF calculations the active space consists in distributing 8 electrons in 10 orbitals, that corresponds to the $\pi$ allyl-like system ( 3 orbitals), the five $d$ orbitals of the transition metal and two orbitals corresponding to the two oxygen lone pairs that interact with the titanium ion. The most relevant $\operatorname{CASSCF}(8,10)$ natural orbitals ${ }^{4}$ (NO's) of OSS and T biradical are those reported in Figure 4 of the Communication, along with the corresponding occupation numbers. The topology of these NO's allows us to assign these orbitals to an allylic-like $\pi$-system $\left(\pi_{1}, \pi_{2}\right.$ and $\pi_{3}$ orbitals) combined with the Ti $d$ orbital, (Ti $(d))$. For OSS state, the $\pi_{1}$ and $\pi_{3}$ orbitals are clearly identified as the bonding and antibonding combinations of the allyl-like $\pi$ system. However, the $\pi_{2}$ orbital (non-bonding in the allyl-like $\pi$-system) is mixed with the $\operatorname{Ti}(d)$ orbital. The natural orbitals, $\pi_{2}+\operatorname{Ti}(d)$ with occupation $1.143 \pi_{2}-\operatorname{Ti}(d)$ with occupation 0.862 , fulfils the biradical structure. Notice from Figure $4 \mathrm{a}$ of the Communication the positive overlap between the $\pi_{2}$ allyl-like and $\operatorname{Ti}(d)$ in the NO with occupation 1.143. This overlap increases as the $\mathrm{Ti} \cdots \mathrm{O}$ bond distance diminishes when OSS evolves to CSS (through TS2) in the valence tautomerism process. The corresponding NO's for the $\mathbf{T}$ state, have a very similar topology with respect to the OSS orbitals.

Mulliken analysis of electron density ${ }^{4}$ in the $\mathbf{T}$ state assigns that the spin densities arising from unpaired electrons are $\mathrm{Ti}(0.98)---\mathrm{O}(0.28)---\mathrm{C}(-0.10)---\mathrm{C}$ $(0.82)$, and less than 0.01 unpaired electrons are located on the remaining atoms. The significant spin density on the $\mathrm{O}-\mathrm{C}-\mathrm{C}$ allylic-like group justify the splittings of the observed EPR signals due to interaction with one or two $\mathrm{H}$ nucleus directly bonded to $\mathrm{C} 4$, quite distorted by the large spreading of this spin density, as well as the slightly anomalous displacements of the corresponding NMR shifts.

The different minima and transition structures have been connected by using the Intrinsic Reaction Coordinate (IRC) algorithm (fourth order Runge-Kutta variable step method as implemented in GAMESS program $^{8}$ ) with the LANL2DZ basis set and the corresponding levels of theory described above. The effect of basis set size has been checked by performing single point calculations using the $6-31 \mathrm{G}^{*}$ all electron basis set on the $* * / L A N L 2 D Z$ optimized structures described above. The shape of the $\operatorname{CASSCF}(8,10) / 6-31 \mathrm{~g} *$ active orbitals is very similar to the corresponding $\operatorname{CASSCF}(8,10) / \mathrm{LANL} 2 \mathrm{DZ}$. Noticeable modifications of the initial barriers of the 
energy profile are evident although the general qualitative shape is maintained, especially in the open shell region. In Figure 3 of the communication, the relative energy profile we have displayed corresponds to single point energies obtained with the 6-31G* basis set computed at the optimized geometries and ZPE corrections obtained using the LANL2DZ basis set and the levels of theory described above. It is seen that TS2 lies slightly below the energy of CSS (Energy + ZPE values). This can be attributed to differential correlation effects between these structures and the different basis sets employed.

Finally, on the titanium enolate system, CSS, TS2, OSS and T, we have also performed single-point energy calculations employing a limited MRCI approach correlating 32 valence electrons and the LANL2DZ basis set (which corresponds to $\sim 7 \cdot 10^{6} \mathrm{CSF}$ for singlet states). The barrier heights change to $+7.5 \mathrm{kcal} \cdot \mathrm{mol}^{-1}$ between CSS and TS2, to $-2.0 \mathrm{kcal} \cdot \mathrm{mol}^{-1}$ between TS2 and OSS, with the T state at less than 1 $\mathrm{kcal} \cdot \mathrm{mol}^{-1}$. These results suggest that the energy profile remains qualitatively unchanged by dynamic correlation effects although no definitive conclusions can be drawn from these calculations due to the smallness of the basis set and the limited number of electrons correlated in the MRCI expansion. The HF and CASSCF calculations have been performed with the $\mathrm{GAMESS}^{8}$ whereas Molcas6. $4^{9}$ program package has been used to run MRCI calculations. The bonding features of $\mathrm{Ti} \cdots \mathrm{O}$ bonds have been analyzed according to the AIM theory by Bader ${ }^{10}$ employing the AIMPAC program. ${ }^{11}$ The AIM values for critical points are reported in Table S4 and reveal that both $\mathrm{Ti} \cdots \mathrm{O}$ bonds are dative in nature, as can be deduced from the density and laplacian values at the bond critical points. 
Supplementary Tables S2: Cartesian coordinates of the optimized molecular structures of minima and transition states (in $\AA$ ). The titanium enolate intermediate corresponds to the rearrangement of $\alpha$-methoxy ketone with $\mathrm{NH}_{3}$, which is the model reaction used in the present study. All calculations were done at HF/LANL2DZ level except for CSS, TS2, OSS and T states which have been optimized at CASSCF $(8,10) / L A N L 2 D Z$ level.

\section{Table S2.a: M1}

\begin{tabular}{|c|c|c|c|}
\hline \multicolumn{4}{|c|}{ RHF /LANL2DZ } \\
\hline 19 & oms charge $=0$ & $S=0 \quad E=$ & 8609 a.u. \\
\hline $\mathrm{C}$ & -3.690560 & -1.385349 & -0.036019 \\
\hline C & -2.438891 & -0.573174 & -0.051144 \\
\hline C & -2.461962 & 0.919008 & 0.149094 \\
\hline 0 & -1.115569 & 1.375953 & -0.025096 \\
\hline C & -0.955662 & 2.832441 & -0.134498 \\
\hline $\mathrm{o}$ & -1.330268 & -1.090321 & -0.198713 \\
\hline $\mathrm{Ti}$ & 0.498588 & -0.138938 & -0.001505 \\
\hline $\mathrm{Cl}$ & 0.391932 & 0.126978 & -2.301207 \\
\hline $\mathrm{Cl}$ & 1.661557 & -2.030110 & -0.008458 \\
\hline $\mathrm{Cl}$ & 2.098036 & 1.437113 & 0.302428 \\
\hline $\mathrm{Cl}$ & -0.070849 & -0.208426 & 2.295177 \\
\hline $\mathrm{H}$ & -4.574517 & -0.776284 & -0.153327 \\
\hline $\mathrm{H}$ & -3.645146 & -2.132873 & -0.814808 \\
\hline $\mathrm{H}$ & -3.744118 & -1.905970 & 0.913988 \\
\hline $\mathrm{H}$ & -2.816627 & 1.151279 & 1.145578 \\
\hline $\mathrm{H}$ & -3.109507 & 1.380951 & -0.584406 \\
\hline $\mathrm{H}$ & 0.056864 & 3.013810 & -0.435393 \\
\hline $\mathrm{H}$ & -1.643720 & 3.194512 & -0.884322 \\
\hline $\mathrm{H}$ & -1.151863 & 3.270890 & 0.832190 \\
\hline
\end{tabular}

Table S2.b: M2

\begin{tabular}{|c|c|c|c|}
\hline \multicolumn{4}{|c|}{ /LAI } \\
\hline 23 & atoms charge $=0$ & $S=0 \quad E=-478$ & 5144 a.u. \\
\hline $\mathrm{C}$ & 3.102949 & 0.678417 & -1.800572 \\
\hline $\mathrm{C}$ & 1.884638 & 0.633933 & -0.946007 \\
\hline C & 1.538562 & 1.757404 & -0.007618 \\
\hline 0 & 0.325860 & 1.359870 & 0.656180 \\
\hline $\mathrm{C}$ & -0.027786 & 2.138188 & 1.849206 \\
\hline 0 & 1.041028 & -0.267281 & -1.047975 \\
\hline $\mathrm{Ti}$ & -0.856234 & -0.223853 & -0.281431 \\
\hline $\mathrm{Cl}$ & -0.034492 & -1.529014 & 1.480365 \\
\hline $\mathrm{Cl}$ & -1.569729 & -1.931314 & -1.516941 \\
\hline $\mathrm{Cl}$ & -2.724705 & 0.394946 & 0.856096 \\
\hline $\mathrm{Cl}$ & -1.185476 & 1.428742 & -1.945458 \\
\hline $\mathrm{H}$ & 3.389866 & -0.321869 & -2.081777 \\
\hline $\mathrm{H}$ & 3.918677 & 1.176428 & -1.300233 \\
\hline $\mathrm{H}$ & 1.373977 & 2.670077 & -0.565612 \\
\hline $\mathrm{H}$ & 2.331250 & 1.885752 & 0.710936 \\
\hline $\mathrm{H}$ & -0.800248 & 1.597383 & 2.359297 \\
\hline $\mathrm{H}$ & 0.850608 & 2.221130 & 2.472246 \\
\hline
\end{tabular}




$\begin{array}{rrrr}\mathrm{H} & -0.383901 & 3.106740 & 1.533199 \\ \mathrm{H} & 2.852668 & 1.226366 & -2.704564 \\ \mathrm{~N} & 3.414777 & -0.668131 & 1.176105 \\ \mathrm{H} & 2.556285 & -1.106128 & 1.455485 \\ \mathrm{H} & 3.990238 & -1.296507 & 0.649604 \\ \mathrm{H} & 3.912973 & -0.289960 & 1.958208\end{array}$

Table S2.c: TS1

RHF / LANL2DZ

$\begin{array}{rrrr}23 & \text { atoms charge }=0 & \mathrm{~S}=0 \mathrm{E}=-478.495337 \mathrm{a} . \mathrm{u} . \\ \mathrm{C} & 3.232642 & 0.810032 & -1.117561 \\ \mathrm{C} & 1.892307 & 0.927935 & -0.718594 \\ \mathrm{C} & 1.390535 & 2.015003 & 0.204869 \\ \mathrm{O} & 0.007900 & 1.710539 & 0.469730 \\ \mathrm{C} & -0.746532 & 2.761564 & 1.161032 \\ \mathrm{O} & 1.008497 & 0.048322 & -1.000971 \\ \mathrm{Ti} & -0.670014 & -0.278242 & -0.063771 \\ \mathrm{Cl} & 0.878985 & -0.883047 & 1.813404 \\ \mathrm{Cl} & -0.863418 & -2.399447 & -0.762772 \\ \mathrm{Cl} & -2.382384 & -0.117235 & 1.452519 \\ \mathrm{Cl} & -1.846472 & 0.718023 & -1.754198 \\ \mathrm{H} & 3.384048 & 0.311749 & -2.063075 \\ \mathrm{H} & 3.607571 & -0.268557 & -0.309387 \\ \mathrm{H} & 1.460046 & 2.976444 & -0.284240 \\ \mathrm{H} & 1.949134 & 2.026746 & 1.129314 \\ \mathrm{H} & -1.784904 & 2.507262 & 1.082135 \\ \mathrm{H} & -0.436612 & 2.781792 & 2.194602 \\ \mathrm{H} & -0.547849 & 3.701296 & 0.666449 \\ \mathrm{H} & 3.873008 & 1.659589 & -0.948052 \\ \mathrm{~N} & 3.849018 & -1.409818 & 0.355760 \\ \mathrm{H} & 3.040605 & -1.545042 & 0.949746 \\ \mathrm{H} & 3.918108 & -2.165739 & -0.303610 \\ \mathrm{H} & 4.687568 & -1.347850 & 0.905412\end{array}$

Table S2.d: CSS

\begin{tabular}{|c|c|c|c|}
\hline \\
\hline \multicolumn{4}{|c|}{$\begin{array}{l}\operatorname{CASSCF}(8,10) / \text { LANL2DZ } \\
18 \text { atoms charge }=-1 \quad S=0 \quad E=-422\end{array}$} \\
\hline $\mathrm{C}$ & -3.453272 & -1.304972 & -0.918727 \\
\hline C & -2.433892 & -0.563519 & -0.440124 \\
\hline $\mathrm{C}$ & -2.483566 & 0.736271 & 0.325241 \\
\hline 0 & -1.159594 & 1.287545 & 0.215532 \\
\hline $\mathrm{C}$ & -1.018627 & 2.712190 & 0.462277 \\
\hline $\mathrm{O}$ & -1.108861 & -1.003289 & -0.641086 \\
\hline $\mathrm{Ti}$ & 0.423341 & -0.199590 & -0.067718 \\
\hline $\mathrm{Cl}$ & 0.699090 & 0.915198 & -2.235115 \\
\hline $\mathrm{Cl}$ & 1.839499 & -2.005500 & -0.512310 \\
\hline $\mathrm{Cl}$ & 1.932690 & 1.399613 & 0.991833 \\
\hline $\mathrm{Cl}$ & -0.313790 & -0.935463 & 2.222394 \\
\hline $\mathrm{H}$ & -4.470446 & -0.987961 & -0.793499 \\
\hline $\mathrm{H}$ & -3.261312 & -2.227741 & -1.427302 \\
\hline $\mathrm{H}$ & -2.707099 & 0.568975 & 1.367857 \\
\hline
\end{tabular}




$\begin{array}{lllr}\mathrm{H} & -3.198553 & 1.417891 & -0.113932 \\ \mathrm{H} & -0.032603 & 2.984425 & 0.142391 \\ \mathrm{H} & -1.769622 & 3.233970 & -0.117411 \\ \mathrm{H} & -1.135236 & 2.898616 & 1.520230\end{array}$

Table S2.e: TS2

\begin{tabular}{rrrr}
\multicolumn{4}{c}{ CASSCF $(8,10) / L A N L 2 D Z$} \\
18 & atoms charge $=-1$ & \multicolumn{3}{l}{$\mathrm{S}=0$} & $\mathrm{E}=-422.003747 \mathrm{a} . \mathrm{u}$. \\
$\mathrm{C}$ & -3.450362 & 1.608449 & 0.026952 \\
$\mathrm{C}$ & -2.444362 & 0.709720 & 0.023480 \\
$\mathrm{C}$ & -2.536737 & -0.796609 & 0.009848 \\
$\mathrm{O}$ & -1.191774 & -1.294563 & -0.018291 \\
$\mathrm{C}$ & -1.089424 & -2.744065 & -0.054102 \\
$\mathrm{O}$ & -1.117184 & 1.165514 & 0.033281 \\
$\mathrm{Ti}$ & 0.425213 & 0.204745 & 0.003838 \\
$\mathrm{Cl}$ & 0.188405 & -0.062340 & 2.460069 \\
$\mathrm{Cl}$ & 1.846046 & 2.058594 & 0.036338 \\
$\mathrm{Cl}$ & 2.039742 & -1.627172 & -0.048920 \\
$\mathrm{Cl}$ & 0.156233 & 0.047614 & -2.458808 \\
$\mathrm{H}$ & -4.474656 & 1.289386 & 0.017934 \\
$\mathrm{H}$ & -3.238799 & 2.658180 & 0.037838 \\
$\mathrm{H}$ & -3.060693 & -1.143491 & -0.870687 \\
$\mathrm{H}$ & -3.029230 & -1.162153 & 0.900964 \\
$\mathrm{H}$ & -0.044692 & -2.981612 & -0.058269 \\
$\mathrm{H}$ & -1.570542 & -3.145160 & 0.828779 \\
$\mathrm{H}$ & -1.567102 & -3.100254 & -0.957616
\end{tabular}

\section{Table S2.f: OSS}

\begin{tabular}{rrrr}
\multicolumn{4}{c}{ CASSCF $(8,10) / L A N L 2 D Z$} \\
18 atoms charge $=-1$ & \multicolumn{3}{l}{$\mathrm{S}=0$ E $=-422.008535 \mathrm{a} . \mathrm{u}}$. \\
$\mathrm{C}$ & -3.766577 & 0.832446 & 0.817447 \\
$\mathrm{C}$ & -2.496986 & 0.309534 & 0.425152 \\
$\mathrm{C}$ & -2.370446 & -0.880895 & -0.501302 \\
$\mathrm{O}$ & -1.001907 & -1.291657 & -0.469018 \\
$\mathrm{C}$ & -0.733595 & -2.688315 & -0.786159 \\
$\mathrm{O}$ & -1.410489 & 0.857637 & 0.854623 \\
$\mathrm{Ti}$ & 0.525113 & 0.184137 & 0.056706 \\
$\mathrm{Cl}$ & 0.645857 & -1.266676 & 2.097757 \\
$\mathrm{Cl}$ & 1.629146 & 2.074495 & 0.934184 \\
$\mathrm{Cl}$ & 2.227541 & -1.055561 & -1.173613 \\
$\mathrm{Cl}$ & -0.439413 & 1.292605 & -2.030564 \\
$\mathrm{H}$ & -4.683169 & 0.394590 & 0.473353 \\
$\mathrm{H}$ & -3.796738 & 1.693942 & 1.453004 \\
$\mathrm{H}$ & -2.640310 & -0.599612 & -1.508779 \\
$\mathrm{H}$ & -3.000734 & -1.689562 & -0.153941 \\
$\mathrm{H}$ & 0.316869 & -2.841693 & -0.637497 \\
$\mathrm{H}$ & -1.308019 & -3.308933 & -0.111728 \\
$\mathrm{H}$ & -1.000458 & -2.865591 & -1.819047
\end{tabular}




\section{Table S2.g: T}

\begin{tabular}{rrrr}
\multicolumn{4}{c}{ CASSCF $(8,10) / L A N L 2 D Z$} \\
18 & atoms Charge $=-1$ & \multicolumn{3}{l}{$\mathrm{S}=1$} & $\mathrm{E}=-422.007097 \mathrm{a} . \mathrm{u}$. \\
$\mathrm{C}$ & -3.811335 & 0.797843 & 0.782093 \\
$\mathrm{C}$ & -2.518542 & 0.300677 & 0.411789 \\
$\mathrm{C}$ & -2.364254 & -0.871741 & -0.533462 \\
$\mathrm{O}$ & -0.995950 & -1.283194 & -0.480733 \\
$\mathrm{C}$ & -0.727146 & -2.681166 & -0.794194 \\
$\mathrm{O}$ & -1.453100 & 0.852700 & 0.876161 \\
$\mathrm{Ti}$ & 0.538244 & 0.179655 & 0.055862 \\
$\mathrm{Cl}$ & 0.633438 & -1.268048 & 2.093084 \\
$\mathrm{Cl}$ & 1.631380 & 2.070720 & 0.942604 \\
$\mathrm{Cl}$ & 2.242766 & -1.058761 & -1.167683 \\
$\mathrm{Cl}$ & -0.425654 & 1.315930 & -2.007106 \\
$\mathrm{H}$ & -4.711229 & 0.354726 & 0.402547 \\
$\mathrm{H}$ & -3.871436 & 1.646451 & 1.432763 \\
$\mathrm{H}$ & -2.612856 & -0.572821 & -1.541333 \\
$\mathrm{H}$ & -3.000002 & -1.688130 & -0.215202 \\
$\mathrm{H}$ & 0.320940 & -2.838315 & -0.633389 \\
$\mathrm{H}$ & -1.311163 & -3.300165 & -0.126631 \\
$\mathrm{H}$ & -0.982394 & -2.857836 & -1.830222
\end{tabular}

Supplementary Table S3: Total energy (in hartrees) and ZPE correction (in $\mathrm{kcal} \cdot \mathrm{mol}^{-1}$ ) of the reported structures using the two sets of basis functions and methods described in the text.

\begin{tabular}{cccccc} 
& & \multicolumn{2}{c}{ LANL2DZ } & & 6-31G* \\
\cline { 3 - 4 } Structure & Method & Energy & ZPE & & Energy \\
\hline M1 & HF & -422.328609 & 92.6 & & -2992.368808 \\
M2 & HF & -478.525144 & 110.0 & & -3048.565760 \\
TS1 & HF & -478.495337 & 108.1 & & -3048.523235 \\
$\mathrm{CSS}+\mathrm{NH}_{4}^{+}$ & $\mathrm{HF}$ & -478.544134 & 112.6 & & -3048.551803 \\
$\mathrm{CSS}$ & $\mathrm{CASSCF}(8,10)$ & -422.005175 & 82.8 & & -2991.981902 \\
$\mathrm{TS} 2$ & $\mathrm{CASSCF}(8,10)$ & -422.003747 & 82.1 & & -2991.981324 \\
$\mathrm{OSS}$ & $\mathrm{CASSCF}(8,10)$ & -422.008535 & 82.7 & & -2992.002565 \\
$\mathrm{~T}$ & $\mathrm{CASSCF}(8,10)$ & -422.007097 & 82.6 & & -2992.045801 \\
$\mathrm{NH}_{4}{ }^{+}$ & $\mathrm{HF}$ & -56.528179 & 33.9 & & -56.529629 \\
$\mathrm{NH}_{3}$ & $\mathrm{HF}$ & -56.180414 & 22.9 & & -56.178355 \\
\hline
\end{tabular}


Supplementary Table S4: AIM analysis of the M1 (HF/LANL2DZ level), CSS, OSS and T states (CASSCF $(8,10) / L A N L 2 D Z$ level) in the maxima between Ti and $O$ atoms. Numbers correspond to the $\rho, \nabla 2 \rho$ and $\varepsilon$ values (i.e.: density, laplacian and ellipticity) in the bond critical points shown. The bonding features have been analyzed according the Bader's AIM theory ${ }^{10}$ employing the AIMPAC program. ${ }^{11}$

\begin{tabular}{|c|c|c|c|c|}
\hline & & $\rho$ & $\nabla^{2} \rho$ & $\varepsilon$ \\
\hline \multirow{2}{*}{ M1 } & MeO--Ti & 0.0522 & 0.2358 & 0.0446 \\
\hline & $\mathrm{C}=\mathrm{O}--\mathrm{Ti}$ & 0.0729 & 0.3504 & 0.0219 \\
\hline \multirow{2}{*}{ CSS } & MeO--Ti & 0.0520 & 0.2654 & 0.1190 \\
\hline & $\mathrm{C}=\mathrm{O}--\mathrm{Ti}$ & 0.1380 & 0.6610 & 0.3000 \\
\hline \multirow{2}{*}{ OSS } & MeO--Ti & 0.0479 & 0.2823 & 0.0995 \\
\hline & $\mathrm{C}=\mathrm{O}--\mathrm{Ti}$ & 0.0502 & 0.2635 & 1.1480 \\
\hline \multirow{2}{*}{$\mathbf{T}$} & MeO--Ti & 0.0503 & 0.2640 & 0.0804 \\
\hline & $\mathrm{C}=\mathrm{O}--\mathrm{Ti}$ & 0.0414 & 0.2386 & 1.0810 \\
\hline
\end{tabular}




\section{References:}

[1] (a) M. T. Reetz, Acc. Chem. Res. 1993, 26, 462-468; (b) P. G. Cozzi, E. Solari, C. Floriani, A. Chiesi-Villa, C. Rizzoli, Chem. Ber. 1996, 129, 13611368.

[2] (a) P. J. Hay, W. R. Wadt, J. Chem. Phys. 82, 270-283 (1985); (b)P. J. Hay, W. R. Wadt, J. Chem. Phys. 82, 299-310 (1985); (c) T. H. Dunning, Jr., P. J. Hay in Methods of Electronic Structure Theory, Vol. 2 (Ed. H. F. Schaeffer III), pp. 1-27 (Plenum Press, New York, 1977).

[3] The all electron basis sets correspond to [4s/2s] for $\mathrm{H}$; [10s4p1d/3s $2 \mathrm{p} 1 \mathrm{~d}]$ for $\mathrm{C}$, $\mathrm{N}$, and $\mathrm{O}$ reported by P.C. Hariharan and J.A. Pople, Theoret. Chimica Acta 28, 213-222 (1973); to [16s10p1d/4s3p1d] for Cl reported by M.M. Francl, W.J. Petro, W.J. Hehre, J.S.Binkley, M.S. Gordon, D.J. DeFrees and J.A. Pople, J. Chem. Phys. 77, 3654-3665 (1982) and [22s16p4d1f/5s4p2d1f] for Ti reported by V. Rassolov, J.A. Pople, M. Ratner and T.L. Windus, J. Chem. Phys. 109, 1223-1229 (1998).

[4] R. McWeeny, Methods of Molecular Quantum Mechanics (Academic Press, New York, 1989).

[5] P. E. M. Siegbahn, J. Chem. Phys. 72, 1647-1656 (1980).

[6] F. Illas, I. de P.R. Moreira, J. M. Bofill, M. Filatov, Phys. Rev. B 70, 132414 (2004).

[7] (a) P. R. Schreiner, Angew. Chem. Int. Ed. Engl. 46, 4217-4219 (2007); (b) M. D. Wodrich, C. Corminboeu, P. R. Schreiner, A. A. Fokin, and P. von Ragué Schleyer, Org. Lett. 9, 1851-1854 (2007).

[8] "General atomic and molecular electronic structure system" M. W. Schmidt, K. K. Baldridge, J. A. Boatz, S. T. Elbert, M. S. Gordon, J. H. Jensen, S. Koseki, N. Matsunaga, K. A. Nguyen, S. Su, T. L. Windus, M. Dupuis, J. A. Montgomery Jr, J. Comput. Chem. 14, 1347-1363 (1993). GAMESS Version 2004.

[9] "MOLCAS: a program package for computational chemistry" G. Karlström, R. Lindh, P.-Å. Malmqvist, B. O. Roos, U. Ryde, V. Veryazov, P.-O. Widmark, M. Cossi, B. Schimmelpfennig, P. Neogrady, L. Seijo, Comput. Material Sci. 28, 222-239 (2003), MOLCAS Version 6.4.

[10] R. F. W. Bader, Atoms in Molecules (Clarendon Press, Oxford, 1990).

[11] "Calculation of the average properties of atoms in molecules. II" F. W. Biegler-König, R. F. W. Bader, and T.-H. Tang, J. Comput. Chem. 3, 317-328 (1982), AIMPAC Version 94, Revision B. 